\title{
Effects of raloxifene and estrogen on bioactive IGF1 in GH-deficient women
}

\author{
Vita Birzniece ${ }^{1,2,3}$, Nils Erik Magnusson ${ }^{5}$, Ken K Y Ho ${ }^{1,2,4}$ and Jan Frystyk ${ }^{5}$ \\ 'Department of Endocrinology, Garvan Institute of Medical Research, St Vincent's Hospital, Sydney, New South \\ Wales, Australia, ${ }^{2}$ University of New South Wales, Sydney, New South Wales, Australia, ${ }^{3}$ School of Medicine, \\ University of Western Sydney, Sydney, New South Wales, Australia, ${ }^{4}$ Centres for Health Research, Princess Alexandra \\ Hospital, Brisbane, Queensland, Australia and ${ }^{5}$ Medical Research Laboratory, Department of Clinical Medicine, \\ Faculty of Health, Aarhus University, DK-8000 Aarhus C, Denmark
}

Correspondence
should be addressed
to J Frystyk
Email
JAN.FRYSTYK@KI.AU.DK

\begin{abstract}
Context: GH action is attenuated by estrogens and selective estrogen receptor modulators (SERMs) administered orally. During GH therapy in hypopituitary women, co-treatment with raloxifene, a SERM, induced a smaller gain in lean body mass (LBM) compared with estrogen, despite an equal reduction in IGF1. As a higher IGF-binding protein-3 (IGFBP3) level was observed with raloxifene co-treatment, we hypothesize that an increase in IGFBP3 reduced IGF1 bioactivity causing the attenuated anabolic effect.

Objective: To assess the effects of $17 \beta$-estradiol $\left(E_{2}\right)$ and raloxifene on bioactive IGF1.

Design: In study 1, $12 \mathrm{GH}$-deficient (GHD) women were randomized to raloxifene $120 \mathrm{mg} /$ day or $\mathrm{E}_{2} 4 \mathrm{mg} /$ day for 1 month. In study 2, $16 \mathrm{GHD}$ women were randomized to 1 month GH treatment alone $(0.5 \mathrm{mg} / \mathrm{day})$ and in combination with raloxifene (60 mg/day) or $E_{2}(2 \mathrm{mg} /$ day). We measured bioactive IGF1, immunoreactive IGF1 and IGF2, and IGFBP3 immunoreactivity and fragmentation.

Results: Raloxifene and estrogen suppressed $(P<0.05)$ total IGF1 equally in GHD and GH-replaced hypopituitary women. In GHD patients, neither raloxifene nor estrogen affected bioactive IGF1. GH significantly increased IGF1 bioactivity, an effect attenuated by co-treatment with raloxifene $(\Delta-23 \pm 7 \%, P<0.01)$ and estrogen $(\Delta-26 \pm 3 \%, P=0.06)$. Total IGF1 correlated $\left(r^{2}=0.54, P<0.001\right)$ with bioactive IGF1, which represented $3.1 \pm 0.2 \%$ of the total IGF1, irrespective of the treatments. Total IGF2 was unchanged by raloxifene and estrogen treatment. IGFBP3 was significantly higher during raloxifene administration, whereas no differences in IGFBP3 fragmentation were observed.

Conclusion: Raloxifene effect on bioactive IGF1 is similar to that of estrogen despite higher IGFBP3 levels during raloxifene administration. We conclude that the observed different effects on LBM between raloxifene and estrogen treatments cannot be explained by differences in IGF1 bioactivity.
\end{abstract}

\section{Introduction}

Growth hormone (GH) stimulates hepatic insulin-like growth factor 1 (IGF1) production, which then acts on peripheral tissues to induce anabolic effects. Oral administration of estrogen or estrogen compounds, such as selective estrogen receptor modulators (SERMs), attenuates GH action via a first-pass effect by inhibiting hepatic GH receptor signaling, resulting in a fall in IGF1
(C) 2014 European Society of Endocrinology Printed in Great Britain level $(1,2,3,4)$. We have recently reported that during GH replacement therapy in hypopituitary women, co-treatment with raloxifene, one of the most commonly used SERMs, led to a smaller gain in lean body mass (LBM) than GH co-treatment with estrogen (3). Thus, raloxifene administration resulted in a greater attenuating effect on the GH-induced anabolism than estrogen. 
Previous studies in GH-deficient (GHD) women show that IGF1 is significantly reduced by both estrogen and raloxifene administration, with the reduction in IGF1 being similar between the treatments (2). Thus, the differential effect on LBM by raloxifene and estrogen cannot be explained by differences in circulating IGF1 levels. However, estrogen and raloxifene affect IGF-binding protein-3 (IGFBP3) differently. Estrogen reduces IGFBP3 levels, whereas raloxifene has an opposite stimulatory effect (2).

IGF1 circulates almost entirely (>99\%) bound to a family of binding proteins. IGFBP3 is the most abundant, binding $75-90 \%$ of circulating IGF1 (5). Thus, changes in IGFBP3 levels are likely to affect the bioavailability of IGF1. However, changes in immunoreactive IGFBP3 are not exclusively caused by changes in intact molecules, but may result from proteolysis of IGFBP3 (6). As the emerging fragments of IGFBP3 exhibit lower affinity for IGF1, free IGF1 increases. Thus, higher levels of intact IGFBP3 can variably affect the bioavailability of IGF1 to activate the IGF1 receptor.

We propose that the differences in lean mass in GHD women observed between raloxifene and $17 \beta$-estradiol $\left(E_{2}\right)$ treatment are secondary to changes in IGF1 bioactivity arising from their differing effects on the concentration of IGFBP3 during GH therapy. The aim of this study was to compare the effects of raloxifene and $\mathrm{E}_{2}$ on bioactive IGF1. We hypothesized that higher IGFBP3 concentration during raloxifene administration reduces IGF1 bioactivity.

\section{Subjects and methods}

\section{Study participants}

GHD women with hypogonadism were recruited from the Endocrine Outpatient Clinic, St Vincent's Hospital in Sydney, Australia $(1,2)$. All subjects had GHD diagnosed for at least 1 year prior to the study. GH deficiency was confirmed by the insulin tolerance test as defined by a peak GH response to insulin-induced hypoglycemia of $<3 \mu \mathrm{g} / \mathrm{l}$ (7). None of the patients was receiving $\mathrm{GH}$ replacement or had received $\mathrm{GH}$ within 1 year before commencement of the study. Subjects were withdrawn from estrogen replacement for at least 2 months before commencement of the study. Before and throughout the study, subjects received standard thyroid hormone and cortisol replacement for thyroid and adrenal deficiencies respectively. The doses of replacement were unchanged throughout the study. All subjects were instructed to follow their usual diet and physical activity as well as continuing their usual medications or supplements throughout the study.

The Human Research Ethics Committee of St Vincent's Hospital approved studies that were conducted in accordance with the principles of the Declaration of Helsinki. All subjects gave written informed consent. The second study was registered with the Australian and New Zealand Clinical Trials Registry (ACTRN12605000532606).

\section{Study design}

We compared the effects of raloxifene and $\mathrm{E}_{2}$ in two openlabel, crossover studies, some of the results of which have been published previously $(1,2)$. In the first study, $12 \mathrm{GHD}$ women were randomized to treatment with raloxifene (Evista, Eli Lilly Australia; $120 \mathrm{mg} /$ day) or $\mathrm{E}_{2} 4 \mathrm{mg} /$ day, each for 4 weeks (Fig. 1) (1). After a 4 -week washout phase, the subjects were crossed over to the alternate treatment. In the second study, 16 GHD women were randomized to a 4-week treatment with GH alone (Humatrope, Eli Lilly Australia; $0.5 \mathrm{mg} /$ day) and in combination with raloxifene (60 mg/day) or $E_{2}$ (2 mg/day; Fig. 1) (2). The order of $\mathrm{GH}$ therapy alone and combined treatment with $\mathrm{E}_{2}$ or raloxifene was randomized. For both studies, medroxyprogesterone acetate (10 mg daily) was administered for 10 days immediately after the estrogen treatment phases to induce withdrawal bleeding.

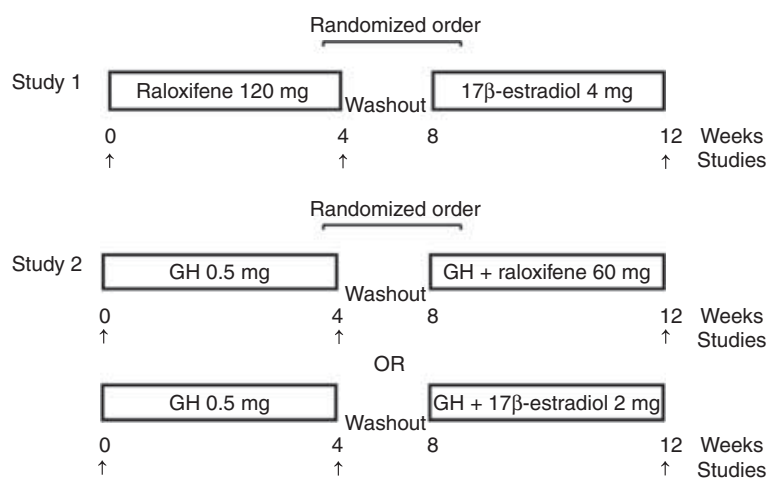

\section{Figure 1}

Study protocol. In the first study, 12 GHD women were randomized to raloxifene ( $120 \mathrm{mg} /$ day) or $17 \beta$-estradiol $\left(E_{2}\right)$ (4 mg/day) treatment. In the second study, 16 GHD women were randomized to $\mathrm{GH}$ treatment alone $(0.5 \mathrm{mg} /$ day $)$ or $\mathrm{GH}$ in combination with raloxifene ( $60 \mathrm{mg} / \mathrm{day})$ or $\mathrm{E}_{2}(2 \mathrm{mg} / \mathrm{day})$. The order of treatments was randomized. The duration of treatments was 4 weeks, followed by a 4-week washout period. Serum was analyzed at baseline and after each treatment period. 
At baseline and at the end of each treatment phase, blood was drawn for measurement of bioactive IGF1, immunoreactive IGF1, IGFBP3, fragmentation of IGFBP3, and IGF2. All investigations were carried out after an overnight fast.

\section{Laboratory analysis}

All the samples for any individual were measured blinded and in the same assay run for each analyte.

IGF1 bioactivity - Bioactive IGF1 levels were determined by an IGF1 kinase receptor activation (KIRA) assay as originally described (8) with modifications (6). In brief, HEK 293 cells transfected with the human IGF1R gene were stimulated with serum or recombinant human (rh)IGF1 standards (WHO 02/254) under physiological conditions $\left(37^{\circ} \mathrm{C}\right.$ and $\left.\mathrm{pH} 7.4\right)$, inducing the binding of IGF1 to its receptor and subsequent receptor tyrosine auto-phosphorylation. The cells were then lysed, transferred to a sandwich assay detecting phosphorylated IGF1Rs by an anti-phosphotyrosine antibody, and quantified in a time-resolved immunofluorometric assay (TR-IFMA). This assay measures activated IGF1Rs through phosphorylation. The within-assay $\mathrm{CV}$ was $<7 \%$, and the between-assay CV $15 \%$ at $140 \mathrm{pmol} / \mathrm{l}$ (8). The bioactive IGF1 levels were expressed as microgram per liter and converted as follows: $1 \mu \mathrm{g} / \mathrm{l}=0.131 \mathrm{nmol} / \mathrm{l}$.

Serum total IGF1 levels were measured by RIA after acid ethanol extraction using a rhIGF1 standard, as described previously $(1,2,7)$. The CV for IGF1 were $8.3 \%$ at $14.7 \mathrm{nmol} / 1$ and $7.4 \%$ at $28.6 \mathrm{nmol} / 1$.

Serum IGF2 was measured by TR-IFMA, as described previously (9) with slight modifications: the IGF2 assay has been calibrated against the international IGF2 reference preparation WHO 96/538, and the detection antibody was a goat polyclonal antibody (Sigma-Aldrich), which before use has been labeled with europium according to the manufacturer (Perkin Elmer Life Sciences, Turku, Finland). The within-assay $\mathrm{CV}$ was $5.0 \%$ and the between-assay $\mathrm{CV}$ was $10 \%$. Conversion factor for IGF2 is $1 \mu \mathrm{g} / \mathrm{l}=0.130 \mathrm{nmol} / \mathrm{l}$.

For study 1, serum IGFBP3 was measured by RIA (Bioclone, Sydney, Australia) (1). For study 2, IGFBP3 levels were measured by in-house RIA assay as described previously $(2,10)$. SHBG was measured by a commercial kit (Immulite 2000, Diagnostic Products Corp., Los Angeles, CA, USA) (2). Conversion factor for IGFBP3 is $1 \mu \mathrm{g} / \mathrm{l}=0.023 \mathrm{nmol} / \mathrm{l}$.
IGFBP3 immunoblotting - Protein abundance was assessed using standard western blotting techniques $(11,12)$. In short, serum samples were diluted 1:40 in laemmli buffer containing 5\% $\beta$-mercaptoethanol (Bio-Rad) and were heated to $94{ }^{\circ} \mathrm{C}$ for $15 \mathrm{~min}$ and left to cool at ambient temperature. A sample volume of $25 \mu \mathrm{l}$ was loaded in duplicate and protein was separated on midi format stain-free SDS gels (12\% Bis-Tris SDS gel, Criterion TGX, Bio-Rad), followed by transferring to a PVDF membrane (Trans-Blot Turbo, Bio-Rad) and immunoblotted. Total protein on the gels and blots were visualized by activation of the stain-free gels for 5 min with u.v.-light using the ChemiDoc system from Bio-Rad. The blots were probed with biotinylated polyclonal antibodies against human IGFBP3 (0.05 mg/l; R\&D Systems, Abingdon, UK), followed by incubation with HRP-streptavidin (R\&D Systems) and developed using chemiluminescence (SuperSignal West Dura, Thermo Scientific, Rockford, IL, USA). Images were analyzed using Image Lab 4.0.1 (Bio-Rad) and mean intensities were calculated and used for semiquantitative analysis. The intact IGFBP3 appeared as a double band at 38 and $42 \mathrm{kDa}$, the main fragmented bands corresponded to $22-23,17-18$, and $15-17 \mathrm{kDa}$ respectively. To yield an estimate of the degradation of IGFBP3, the sum of intensities of the fragmented bands was expressed as a percentage of the total intensity of IGFBP3.

\section{Statistical analysis}

Within-group treatment effects of $\mathrm{GH}$ alone and $\mathrm{GH}$ combined with raloxifene or $\mathrm{E}_{2}$ were assessed using paired t-tests with Bonferroni's correction. Between-group differences comparing the effects of estrogen and raloxifene were analyzed using the unpaired $t$-test. Results were expressed as means with s.E.M. and a $P$ value of $<0.05$ was considered to be significant. Regression analysis was used to determine correlations between the endpoint measures. Statistical analysis was undertaken using the statistical software package SPSS Statistics 20 (IBM Corp., Amonk, NY, USA).

\section{Results}

\section{Baseline characteristics and the effects of $\mathrm{GH}$}

The baseline information of subjects and IGF status from studies 1 and 2 are summarized in Table 1. At baseline, there was no significant difference in any parameters between the groups assigned to $\mathrm{E}_{2}$ and raloxifene treatments. 
Table 1 Baseline characteristics of study 1 and study 2 participants and the effects of $\mathrm{GH}$ administration $(0.5 \mathrm{mg} /$ day) for 4 weeks in $\mathrm{GH}$-deficient patients.

\begin{tabular}{|c|c|c|c|}
\hline & \multirow{2}{*}{$\begin{array}{l}\text { Study } 1 \\
\text { Baseline }\end{array}$} & \multicolumn{2}{|c|}{ Study 2} \\
\hline & & Baseline & $\mathrm{GH}$ \\
\hline Age (years) & $43.9 \pm 3.9$ & $44.8 \pm 3.3$ & NA \\
\hline BMI $\left(\mathrm{kg} / \mathrm{m}^{2}\right)$ & $30.4 \pm 2.0$ & $31.3 \pm 1.8$ & $31.6 \pm 1.8$ \\
\hline IGF1 (nmol/l) & $9.8 \pm 1.6$ & $8.8 \pm 1.2$ & $28.5 \pm 2.9 *$ \\
\hline IGFBP3 (nmol/l) & $50.5 \pm 7.4$ & $47.2 \pm 4.7$ & $73.0 \pm 4.6^{*}$ \\
\hline IGFBP3 fragmentation (\%) & $66.4 \pm 11.1$ & $25.0 \pm 8.9$ & $17.3 \pm 6.7$ \\
\hline IGF1:IGFBP3 molar ratio & $0.20 \pm 0.02$ & $0.19 \pm 0.03$ & $0.39 \pm 0.03 *$ \\
\hline Bioactive IGF1 (nmol/l) & $0.19 \pm 0.02$ & $0.25 \pm 0.03$ & $0.66 \pm 0.06^{*}$ \\
\hline IGF2 (nmol/l) & $47.5 \pm 5.6$ & $68.0 \pm 5.0$ & $80.3 \pm 5.3^{*}$ \\
\hline SHBG $(\mathrm{mmol} / \mathrm{l})$ & $36.8 \pm 8.7$ & $37.2 \pm 7.2$ & $34.9 \pm 6.3$ \\
\hline
\end{tabular}

*Significant $(P<0.01)$ difference compared with the respective baseline.

In GHD women, GH replacement for 4 weeks resulted in a significant $(P<0.01)$ increase in IGF1 by $293 \pm 60 \%$, IGFBP3 by $72 \pm 13 \%$, IGF1:IGFBP3 molar ratio by $130 \pm$ $28 \%$, bioactive IGF1 by $230 \pm 52 \%$, and IGF2 by $21 \pm 6 \%$ (Table 1). GH therapy did not significantly affect IGFBP3 fragmentation.

At baseline and throughout the study, bioactive IGF1 significantly correlated with the total IGF1 levels $\left(r^{2}=0.54 ; P<0.001 ;\right.$ Fig. $\left.2 \mathrm{C}\right)$. The change in total IGF1 levels during $\mathrm{GH}$ replacement was closely followed by a similar change in the bioactivity of IGF1 (Fig. 2A and B). The concentration of bioactive IGF1 constituted $3.1 \pm$ $0.2 \%$ of that of total IGF1, irrespective of the GH status.

\section{Comparison between raloxifene and $E_{2}$}

Total IGF1 - In GHD women (study 1), both raloxifene and estrogen significantly reduced total IGF1 levels, as reported previously (1). The magnitude of the reduction was not significantly different between raloxifene and estrogen treatments (Table 2 and Fig. 3A). In GH-replaced hypopituitary women (study 2), total IGF1 fell significantly during raloxifene $(P<0.01)$ and estrogen co-treatments $(P<0.01)$ compared with $\mathrm{GH}$ administration alone (2). The mean reductions in total IGF1 compared with GH replacement alone were not significantly different between raloxifene and estrogen co-treatments (Table 2 and Fig. 3A).

Insulin-like growth factor-binding protein-3 > In GHD women (study 1$)$, raloxifene significantly $(P<0.05)$ increased whereas estrogen reduced IGFBP3 levels, and the change between raloxifene and estrogen was significantly different, as reported previously (1).
In GH-replaced women (study 2), co-treatment with estrogen but not raloxifene significantly $(P<0.001)$ reduced IGFBP3 levels compared with $\mathrm{GH}$ administration alone, and the changes were significantly $(P<0.05)$ different between raloxifene and estrogen administration (2). Overall, circulating IGFBP3 levels were significantly higher during raloxifene than during estrogen treatment by 25 and $37 \%$ in study 1 and 2 respectively (Table 2 and Fig. 3B).

IGFBP3 fragmentation - As proteolysis of IGFBP3 modifies IGF1 bioactivity, IGFBP3 fragmentation was measured. In GHD women (study 1), neither estrogen nor raloxifene significantly affected IGFBP3 fragmentation compared with baseline (Table 2). In GH-replaced hypopituitary women (study 2), co-treatment with raloxifene or estrogen also did not significantly change IGFBP3 fragmentation compared with GH treatment alone. The change in IGFBP3 fragmentation was not significantly different between raloxifene and estrogen co-treatments in GHD women $(P=0.77)$ and in GHD women replaced with $\mathrm{GH}$ $(P=0.08$; Table 2).

IGF1:IGFBP3 ratio - In GHD women (study 1), the ratio between IGF1 and IGFBP3 significantly $(P<0.001)$ fell
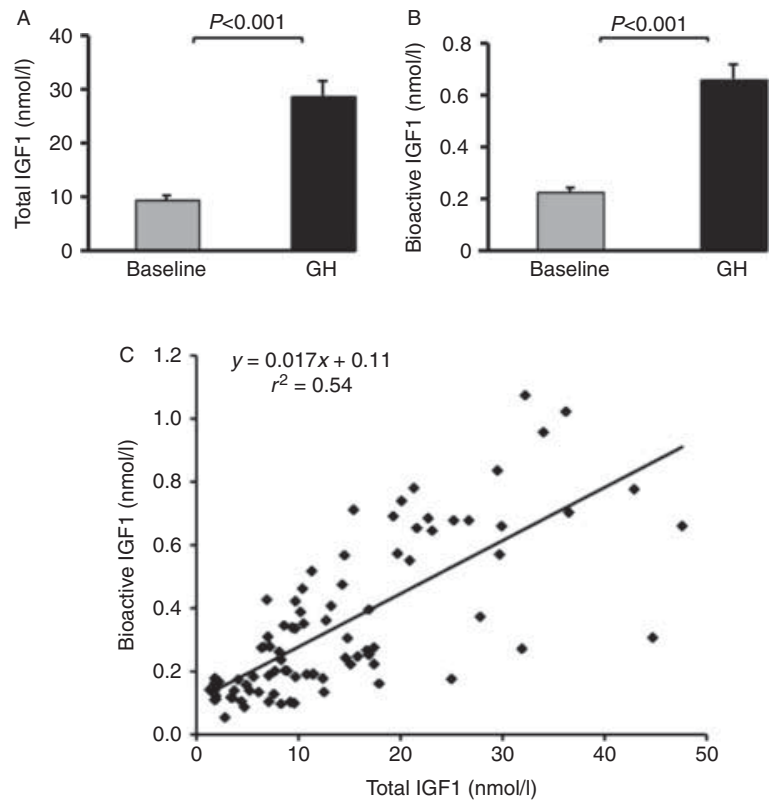

\section{Figure 2}

The effect of $\mathrm{GH}$ replacement ( $0.5 \mathrm{mg} /$ day for 4 weeks) on total (A) and bioactive IGF1 levels (B) in $16 \mathrm{GH}$-deficient women (study 2); (C) linear regression between total and bioactive IGF1 levels $\left(r^{2}=0.54, P<0.001\right)$. 
Table 2 Percent change in endpoint measures during raloxifene and $17 \beta$-estradiol administration in GH-deficient (study 1 ) and GH-replaced hypopituitary women (study 2).

\begin{tabular}{|c|c|c|c|c|}
\hline & \multicolumn{2}{|c|}{ GHD women } & \multicolumn{2}{|c|}{ GH-replaced women } \\
\hline & Raloxifene (120 mg/day) & $17 \beta$-estradiol ( $4 \mathrm{mg} /$ day) & Raloxifene (60 mg/day) & $17 \beta$-estradiol ( $2 \mathrm{mg} /$ day) \\
\hline$\Delta$ IGF1 (\%) & $-24.0 \pm 6.6^{*}$ & $-26.9 \pm 8.2^{*}$ & $-26.6 \pm 6.9 *$ & $-35.0 \pm 6.3^{*}$ \\
\hline$\Delta$ IGFBP3 (\%) & $14.7 \pm 9.5$ & $-4.0 \pm 9.4^{\ddagger}$ & $7.2 \pm 6.2$ & $-20.8 \pm 9.9^{*, \neq}$ \\
\hline$\Delta$ IGFBP3 fragmentation (\%) & $-6.2 \pm 10.6$ & $-9.4 \pm 18.7$ & $1.5 \pm 4.0$ & $26.4 \pm 13.8$ \\
\hline$\Delta$ IGF1/IGFBP3 (\%) & $-30.4 \pm 7.2^{*}$ & $-23.0 \pm 7.0^{\star}, \neq$ & $-30.3 \pm 6.7 *$ & $-10.9 \pm 8.2^{\ddagger}$ \\
\hline$\Delta$ Bioactive IGF1 (\%) & $-11.1 \pm 6.7$ & $5.3 \pm 22.4$ & $-23.0 \pm 6.5^{*}$ & $-25.9 \pm 12.9^{\dagger}$ \\
\hline$\Delta$ IGF2 (\%) & $-5.4 \pm 6.7$ & $-14.3 \pm 10.0$ & $9.9 \pm 4.9$ & $-4.8 \pm 3.4$ \\
\hline$\Delta$ SHBG $(\%)$ & $48.2 \pm 12.6^{*}$ & $251.4 \pm 32.7^{\star \star \neq}$ & $40.9 \pm 8.4$ & $83.9 \pm 34.1$ \\
\hline
\end{tabular}

*Significant $(P<0.01)$ difference compared with the baseline (study 1$)$ and to the GH therapy alone (study 2$) ;{ }^{\dagger} P=0.06$ compared with the GH therapy alone. ${ }^{\ddagger}$ Significant $(P<0.05)$ difference compared with raloxifene administration within the same study.

during raloxifene and estrogen treatments, as reported previously (1). The reduction in the IGFI:IGFBP3 ratio was significantly greater during raloxifene administration $(P<0.05$; Table 2). In GH-replaced hypopituitary women (study 2), only raloxifene co-treatment resulted in a significant reduction in the molar ratio of IGF1:IGFBP3 compared with GH alone $(P<0.01)$, with the ratio being significantly $(P<0.05)$ lower than that during estrogen co-treatment (Table 2) (2).

Bioactive IGF1 • In GHD women (study 1), raloxifene and estrogen treatment did not significantly change bioactive IGF1 levels compared with baseline. In GHreplaced hypopituitary women (study 2), co-treatment with raloxifene and estrogen reduced IGF1 bioactivity by $23 \pm 6.5 \%(P<0.01)$ and $25.9 \pm 12.9 \%(P=0.06)$ compared with GH alone respectively (Table 2 and Fig. 4). There was no significant difference in the reduction of bioactive IGF1 levels between raloxifene and estrogen co-treatments. There was no significant difference $(P=0.2)$ in the proportion of bioactive IGF1 to total IGF1 between raloxifene $(2.9 \pm 0.3 \%)$ and estrogen co-treatments $(3.4 \pm 0.3 \%)$.

Insulin-like growth factor 2 - In GHD women (study 1), raloxifene and estrogen treatment did not significantly change IGF2 levels compared with baseline. In GHreplaced women (study 2), co-treatment with raloxifene and estrogen did not significantly affect IGF2 levels compared with GH treatment alone. There was no significant difference in IGF2 levels between raloxifene and estrogen administration (Table 2).

The change in IGF2 was positively associated with the change in immunoreactive IGFBP3, but the association was very weak $\left(r^{2}=0.11, P<0.05\right)$. There was no significant difference in bioactive IGF1 levels between raloxifene and estrogen treatments, when corrected for circulating IGF2.

\section{Discussion}

This study provides the first comparison of the effects of raloxifene and estrogen on bioactive IGF2. In GHD patients, neither raloxifene nor estrogen affected bioactive
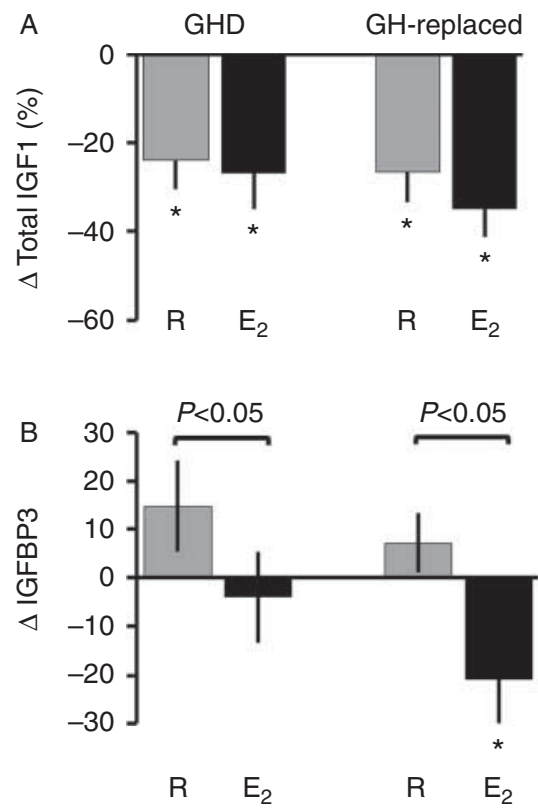

\section{Figure 3}

Changes in total IGF1 (A) and IGFBP3 (B) levels during raloxifene $(\mathrm{R})$ and $17 \beta$-estradiol $\left(\mathrm{E}_{2}\right)$ treatments for 4 weeks in $\mathrm{GH}$-deficient (study 1 ) and GH-replaced hypopituitary women (study 2 ).

* Significant $(P<0.01)$ difference compared with the respective baseline. Data are presented as a percentage change from the respective baseline and expressed as mean \pm s.E.M. 


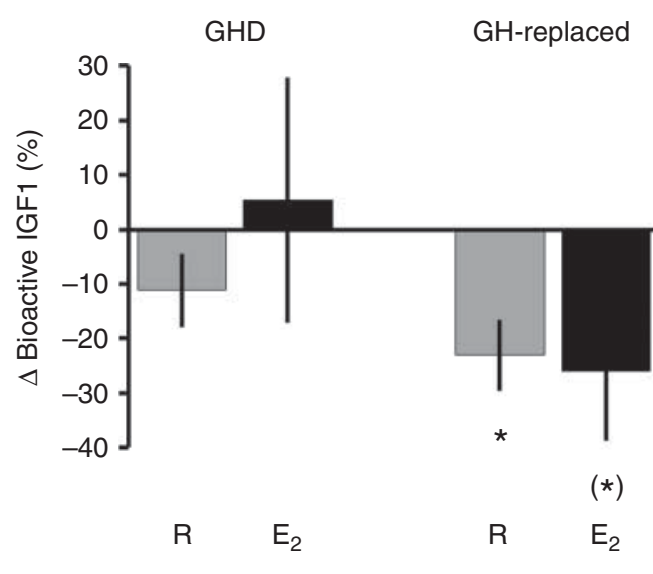

\section{Figure 4}

Changes in bioactive IGF1 during raloxifene (R) and 17 $\beta$ estradiol $\left(E_{2}\right)$ treatments for 4 weeks in GH-deficient (study 1) and GH-replaced women (study 2). In study 2, * indicates significant $(P<0.01)$ difference and $(*)$ indicates $P=0.06$ compared with the $\mathrm{GH}$ replacement alone. Data are presented as a percentage change from the respective baseline and expressed as mean \pm s.E.M.

IGF1. GH significantly increased IGF1 bioactivity, an effect attenuated by co-treatment with raloxifene and estrogen. Moreover, the proportion of bioactive IGF1 to total IGF1 was unaffected by any of the treatments. During raloxifene and estrogen treatments, total IGF1 levels fell to a similar extent, irrespective of the GH status. Total IGF2 was not significantly different between raloxifene and estrogen administration. IGFBP3 was significantly higher during raloxifene administration, whereas no differences in IGFBP3 fragmentation were observed. Thus, raloxifene effect on bioactive IGF1 was similar to that of estrogen despite higher IGFBP3 levels during raloxifene administration.

$\mathrm{GH}$ action is attenuated by oral estrogens and estrogen-like compounds, such as SERMs. We reported recently that during GH therapy in hypopituitary women, co-treatment with raloxifene led to a smaller gain in LBM than GH co-treatment with estrogen (3). We also observed that during raloxifene co-treatment, circulating IGF1 levels were similar while IGFBP3 was higher when compared with estrogen co-treatment (2). We therefore investigated whether higher circulating IGFBP3 levels reduced IGF1 bioactivity during raloxifene treatment. However, there was no significant difference in IGF1 bioactivity between raloxifene and estrogen treatments. Therefore, the greater attenuating effect on LBM during raloxifene administration (3) cannot be explained by differences in IGF1 bioactivity.

IGF1 bioactivity was measured by IGF KIRA assay, which detects phosphorylated IGF1Rs (8). This assay measures IGF1R activation, and therefore comprises a composed entity of free IGF1, IGF2, and IGFs which are readily dissociable, i.e. loosely bound to partly degraded IGFBPs (13). IGF2 is able to interact with the IGF1R and in our assay the cross-reactivity to IGF2 is $12 \%$ (8). We measured IGF2 levels, but no differences in serum IGF2 between raloxifene and estrogen administration were observed. Therefore, changes in IGF2 levels are unlikely to have influenced the measurement of IGFIR activation differently when comparing raloxifene and estrogen.

Insulin modulates IGF1 production. In general, patients with type 1 diabetes, who are characterized by low portal insulin levels, have subnormal IGF1 levels despite an elevated GH secretion. By contrast, in obesity when insulin levels are high, the hepatic production of IGF1 can be maintained at a normal level despite reduced GH secretion $(14,15)$. These observations indicate that insulin regulates the hepatic sensitivity of GH. Moreover, insulin sensitivity appears to play an important role in the modulation of the bioactivity of IGF1. IGF1 bioactivity progressively increases with insulin resistance, an effect which is lost upon progression to overt type 2 diabetes (16). We measured overnight fasting insulin levels in study 2 and observed no significant effect of raloxifene or estrogen administration compared with $\mathrm{GH}$ treatment alone. Thus, it is unlikely that IGF2 and insulin played a major role in the determination of bioactive IGF1 levels in this study.

In vitro studies report a dose-dependent inhibition of the IGF1 bioactivity by IGFBP3 (8). IGFBP3 activates a phosphotyrosine phosphatase, which dephosphorylates the activated IGF1 receptor (17). Therefore, it is conceivable that higher IGFBP3 levels during raloxifene administration in our study affected the bioactivity of IGF1. However, this did not happen and we did not observe reverse association between the two parameters. In vivo, the association between bioactive IGF1 and IGFBP3 is different, showing a positive relationship possibly due to the fact that IGFBP3 is regulated in parallel with IGF1 by the GH (18). However, we observed that both raloxifene and estrogen affect IGF1 bioactivity equally despite significantly higher IGFBP3 levels during raloxifene administration. Moreover, we found that the higher IGFBP3 levels were not due to fragmentation of the binding protein. Thus, there is a distinct increase in intact IGFBP3 during raloxifene administration. 
The liver is a principal site for IGF1 and IGFBP3 production, the regulation of which strongly depends on the hepatic GH action. Raloxifene has a stimulatory effect on IGFBP3, at the same time significantly reducing IGF1 levels. Even though both IGF1 and IGFBP3 are produced by the liver, IGF1 is synthesized by hepatocytes, whereas IGFBP3 is mainly synthesized by Kupffer cells $(19,20,21)$. There is a possibility that raloxifene may affect hepatocytes and Kupffer cells differently; however, to the best of our knowledge there is no evidence supporting this speculation.

Many tissues produce IGFs and IGFBPs locally, which may play even a greater role in the regulation of cell growth and survival than the circulating levels of these proteins (22). There are many factors which stimulate local production of IGFBP3, including TGF $\beta$ (23). Raloxifene activates the TGF $\beta$ gene (24), and tamoxifen, another SERM with similar actions to raloxifene, significantly increases tissue levels of TGF $\beta$ (25). As in vitro studies show that TGF $\beta$ is a very potent stimulant of IGFBP3 synthesis and secretion $(26,27)$, raloxifene-induced increase in IGFBP3 may be mediated at least partly through TGF $\beta$ stimulation. Therefore, we speculate that the increase in circulating IGFBP3 levels during raloxifene administration may originate from a spillover of IGFBP3 from local tissue.

There is increasing evidence that IGFBP3 exert IGF1independent effects on cell growth, survival, and metabolism. IGFBP3 can translocate into the cell, where it interacts with several nuclear receptors (Nurr77, $R X R \alpha$ ), inhibiting cell proliferation and survival; it can also bind to several cell membrane receptors including TGF $\beta$ receptor subtypes (LRP1, TGF $\beta$ RI, TGF $\beta$ RII), inducing pro-apoptotic effects $(5,23,28,29,30)$. There is evidence that IGFBP3 induces insulin resistance and inhibits insulin-stimulated glucose uptake in adipocytes and adipocyte differentiation (31, 32, 33, 34). IGFBP3 may regulate myoblast differentiation and skeletal muscle mass is reduced in IGFBP3 transgenic animals $(35,36)$. In other words, raloxifene increases IGFBP3 levels that are known to have IGF1independent effects on cell proliferation, survival, and metabolism, which may at least partly contribute to the attenuating effect on LBM that we observe during raloxifene treatment.

A weakness of this study relates to small sample size. We cannot exclude that if a larger patient group was studied, some subtle changes could have been deemed statistically significant. Also, effects of raloxifene and estradiol were studied over 4 weeks of administration and we cannot exclude that differences in IGF1 bioactivity may become apparent with longer-term drug administration. We did not find differences between raloxifene and estrogen on IGF1 bioactivity in serum; however, we did not measure tissue IGF1 bioactivity which may differ from that in serum. We also did not measure tissue IGF1 receptor expression, which may be differently regulated by raloxifene and estradiol. However, to the best of our knowledge there are no studies published reflecting differential effect on muscle or liver IGF1 receptor expression by raloxifene and estradiol administration. Finally, we did not measure other IGFBPs which may also influence IGF1 bioactivity. Studies are sparse investigating raloxifene effects on IGFBPs; however, tamoxifen has been shown to increase IGFBP1 and reduce IGFBP2 levels $(37,38)$. Nevertheless, IGFBP3 is the principal binding protein of IGF1 and in this study we report that raloxifene has a specific and unique property of stimulating IGFBP3 levels, the effect being unrelated to an increase in IGFBP3 fragmentation and changes in IGF2.

In summary, estrogen and raloxifene affected bioactive and total IGF1 levels equally while IGFBP3 levels were significantly higher during raloxifene treatment. The proportion of bioactive to total IGF1 was not significantly different between raloxifene and estrogen treatments. We conclude that the difference in the effects on LBM between raloxifene and estrogen cannot be explained by differences in IGF1 bioactivity. The attenuating effect of raloxifene on the $\mathrm{GH}$ anabolic effect is unlikely to involve IGF1 mediation.

\section{Declaration of interest}

The authors declare that there is no conflict of interest that could be perceived as prejudicing the impartiality of the research reported.

\section{Funding}

This work was supported by the Department of Clinical Medicine, Health, Aarhus University, Denmark and the NHMRC of Australia. The study was registered with the Australian New Zealand Clinical Trials Registry (ACTRN12605000532606).

\section{Acknowledgements}

This study was supported by funding from the Department of Clinical Medicine, Health, Aarhus University, Denmark and the NHMRC of Australia. The authors thank Eli Lily Australia for providing GH and raloxifene. They thank James Gibney for his invaluable contribution to the conduct of the clinical studies, Lone Kvist, Elsebeth Hornemann, and Lisa Buus from Medical Research Laboratories, Aarhus University Hospital, Denmark and Kris Tan from Endocrinology Laboratory, Royal Prince Alfred Hospital, Australia for laboratory assistance.
} 


\section{References}

1 Gibney J, Johannsson G, Leung KC \& Ho KK. Comparison of the metabolic effects of raloxifene and oral estrogen in postmenopausal and growth hormone-deficient women. Journal of Clinical Endocrinology and Metabolism 200590 3897-3903. (doi:10.1210/jc.2005-0173)

2 Birzniece V, Meinhardt U, Gibney J, Johannsson G, Baxter RC, Seibel MJ $\&$ Ho KK. Modulatory effect of raloxifene and estrogen on the metabolic action of growth hormone in hypopituitary women. Journal of Clinical Endocrinology and Metabolism 201095 2099-2106. (doi:10.1210/ jc.2009-2743)

3 Birzniece V, Meinhardt UJ, Gibney J, Johannsson G, Armstrong N, Baxter RC \& Ho KK. Differential effects of raloxifene and estrogen on body composition in growth hormone-replaced hypopituitary women. Journal of Clinical Endocrinology and Metabolism 201297 1005-1012. (doi:10.1210/jc.2011-2837)

4 Birzniece V \& Ho KK. Growth and development: patching up a better pill for GH-deficient women. Nature Reviews. Endocrinology 20128 197-198. (doi:10.1038/nrendo.2012.9)

5 Jogie-Brahim S, Feldman D \& Oh Y. Unraveling insulin-like growth factor binding protein-3 actions in human disease. Endocrine Reviews 200930 417-437. (doi:10.1210/er.2008-0028)

6 Reinhard M, Frystyk J, Jespersen B, Bjerre M, Christiansen JS, Flyvbjerg A \& Ivarsen P. Effect of hyperinsulinemia during hemodialysis on the insulin-like growth factor system and inflammatory biomarkers: a randomized open-label crossover study. BMC Nephrology 20131480. (doi:10.1186/1471-2369-14-80)

7 Hoffman DM, O'Sullivan AJ, Baxter RC \& Ho KK. Diagnosis of growth-hormone deficiency in adults. Lancet 1994343 1064-1068. (doi:10.1016/S0140-6736(94)90181-3)

8 Chen JW, Ledet T, Orskov H, Jessen N, Lund S, Whittaker J, De Meyts P, Larsen MB, Christiansen JS \& Frystyk J. A highly sensitive and specific assay for determination of IGF-I bioactivity in human serum.

American Journal of Physiology. Endocrinology and Metabolism 2003284 E1149-E1155.

9 Frystyk J, Dinesen B \& Orskov H. Non-competitive time-resolved immunofluorometric assays for determination of human insulin-like growth factor I and II. Growth Regulation 19955 169-176.

10 Baxter RC \& Martin JL. Radioimmunoassay of growth hormonedependent insulinlike growth factor binding protein in human plasma. Journal of Clinical Investigation 198678 1504-1512. (doi:10.1172/ JCI112742)

11 Laemmli UK. Cleavage of structural proteins during the assembly of the head of bacteriophage T4. Nature 1970227 680-685. (doi:10.1038/ 227680a0)

12 Towbin H, Staehelin T \& Gordon J. Electrophoretic transfer of proteins from polyacrylamide gels to nitrocellulose sheets: procedure and some applications. PNAS 197976 4350-4354. (doi:10.1073/ pnas.76.9.4350)

13 Frystyk J. Quantification of the GH/IGF-axis components: lessons from human studies. Domestic Animal Endocrinology 201243 186-197. (doi:10.1016/j.domaniend.2011.11.005)

14 Hedman CA, Frystyk J, Lindstrom T, Chen JW, Flyvbjerg A, Orskov H \& Arnqvist HJ. Residual $\beta$-cell function more than glycemic control determines abnormalities of the insulin-like growth factor system in type 1 diabetes. Journal of Clinical Endocrinology and Metabolism 200489 6305-6309. (doi:10.1210/jc.2004-0572)

15 Gleeson HK, Lissett CA \& Shalet SM. Insulin-like growth factor-I response to a single bolus of growth hormone is increased in obesity. Journal of Clinical Endocrinology and Metabolism 200590 1061-1067. (doi:10.1210/jc.2004-0501)

16 Brugts MP, van Duijn CM, Hofland LJ, Witteman JC, Lamberts SW \& Janssen JA. Igf-I bioactivity in an elderly population: relation to insulin sensitivity, insulin levels, and the metabolic syndrome. Diabetes 2010 59 505-508. (doi:10.2337/db09-0583)
17 Ricort JM \& Binoux M. Insulin-like growth factor-binding protein-3 activates a phosphotyrosine phosphatase, effects on the insulin-like growth factor signaling pathway. Journal of Biological Chemistry 2002 277 19448-19454. (doi:10.1074/jbc.M200439200)

18 Brugts MP, van den Beld AW, Hofland LJ, van der Wansem K, van Koetsveld PM, Frystyk J, Lamberts SW \& Janssen JA. Low circulating insulin-like growth factor I bioactivity in elderly men is associated with increased mortality. Journal of Clinical Endocrinology and Metabolism 200893 2515-2522. (doi:10.1210/jc.2007-1633)

19 Zimmermann EM, Li L, Hoyt EC, Pucilowska JB, Lichtman S \& Lund PK. Cell-specific localization of insulin-like growth factor binding protein mRNAs in rat liver. American Journal of Physiology. Gastrointestinal and Liver Physiology 2000278 G447-G457.

20 Scharf JG, Ramadori G, Braulke T \& Hartmann H. Cellular localization and hormonal regulation of biosynthesis of insulin-like growth factor binding proteins and of the acid-labile subunit within rat liver. Progress in Growth Factor Research 19956 175-180. (doi:10.1016/0955-2235 (95)00031-3

21 Chin E, Zhou J, Dai J, Baxter RC \& Bondy CA. Cellular localization and regulation of gene expression for components of the insulin-like growth factor ternary binding protein complex. Endocrinology 1994134 2498-2504. (doi:10.1210/en.134.6.2498)

22 Yakar S, Liu JL, Stannard B, Butler A, Accili D, Sauer B \& LeRoith D. Normal growth and development in the absence of hepatic insulin-like growth factor I. PNAS 199996 7324-7329. (doi:10.1073/pnas.96.13. 7324)

23 Yamada PM \& Lee KW. Perspectives in mammalian IGFBP-3 biology: local vs. systemic action. American Journal of Physiology. Cell Physiology 2009296 C954-C976. (doi:10.1152/ajpcell.00598.2008)

24 Yang NN, Venugopalan M, Hardikar S \& Glasebrook A. Identification of an estrogen response element activated by metabolites of $17 \beta$-estradiol and raloxifene. Science 1996273 1222-1225. (doi:10.1126/science.273. 5279.1222)

25 Knabbe C, Lippman ME, Wakefield LM, Flanders KC, Kasid A, Derynck R \& Dickson RB. Evidence that transforming growth factor- $\beta$ is a hormonally regulated negative growth factor in human breast cancer cells. Cell 198748 417-428. (doi:10.1016/0092-8674(87)90193-0)

26 Martin JL \& Baxter RC. Transforming growth factor- $\beta$ stimulates production of insulin-like growth factor-binding protein-3 by human skin fibroblasts. Endocrinology 1991128 1425-1433. (doi:10.1210/ endo-128-3-1425)

27 Massoner P, Haag P, Seifarth C, Jurgeit A, Rogatsch H, Doppler W, Bartsch G \& Klocker H. Insulin-like growth factor binding protein-3 (IGFBP-3) in the prostate and in prostate cancer: local production, distribution and secretion pattern indicate a role in stromal-epithelial interaction. Prostate 200868 1165-1178. (doi:10.1002/pros.20785)

28 Martin JL \& Baxter RC. Signalling pathways of insulin-like growth factors (IGFs) and IGF binding protein-3. Growth Factors 201129 235-244. (doi:10.3109/08977194.2011.614237)

29 Gribben L, Baxter RC \& Marsh DJ. Insulin-like growth factor binding protein-3 inhibits migration of endometrial cancer cells. Cancer Letters 2012317 41-48. (doi:10.1016/j.canlet.2011.11.011)

30 Kim JH, Choi DS, Lee OH, Oh SH, Lippman SM \& Lee HY. Antiangiogenic antitumor activities of IGFBP-3 are mediated by IGF-independent suppression of Erk1/2 activation and Egr-1-mediated transcriptional events. Blood 2011118 2622-2631. (doi:10.1182/ blood-2010-08-299784)

31 Muzumdar RH, Ma X, Fishman S, Yang X, Atzmon G, Vuguin P, Einstein FH, Hwang D, Cohen P \& Barzilai N. Central and opposing effects of IGF-I and IGF-binding protein-3 on systemic insulin action. Diabetes 200655 2788-2796. (doi:10.2337/db06-0318)

32 Kim HS, Ali O, Shim M, Lee KW, Vuguin P, Muzumdar R, Barzilai N \& Cohen P. Insulin-like growth factor binding protein-3 induces insulin resistance in adipocytes in vitro and in rats in vivo. Pediatric Research 200761 159-164. (doi:10.1203/pdr.0b013e31802d8a30) 
33 Chan SS, Twigg SM, Firth SM \& Baxter RC. Insulin-like growth factor binding protein-3 leads to insulin resistance in adipocytes. Journal of Clinical Endocrinology and Metabolism 200590 6588-6595. (doi:10.1210/ jc.2005-0595)

34 Chan SS, Schedlich LJ, Twigg SM \& Baxter RC. Inhibition of adipocyte differentiation by insulin-like growth factor binding protein-3. American Journal of Physiology. Endocrinology and Metabolism 2009296 E654-E663. (doi:10.1152/ajpendo.90846.2008)

35 Foulstone EJ, Savage PB, Crown AL, Holly JM \& Stewart CE. Role of insulin-like growth factor binding protein-3 (IGFBP-3) in the differentiation of primary human adult skeletal myoblasts. Journal of Cellular Physiology 2003195 70-79. (doi:10.1002/ jcp.10227)
36 Silha JV, Gui Y \& Murphy LJ. Impaired glucose homeostasis in insulinlike growth factor-binding protein-3-transgenic mice. American Journal of Physiology. Endocrinology and Metabolism 2002283 E937-E945.

37 Bonanni B, Johansson H, Gandini S, Guerrieri-Gonzaga A, Torrisi R, Sandri MT, Cazzaniga M, Mora S, Robertson C, Lien EA et al. Effect of low dose tamoxifen on the insulin-like growth factor system in healthy women. Breast Cancer Research and Treatment 200169 21-27. (doi:10.1023/A:1012241505717)

38 Helle SI, Mietlowski W, Guastalla JP, Szakolczai I, Bajetta E, Sommer H, Baltali E, Pinter T, Csepreghy M, Ottestad L et al. Effects of tamoxifen and octreotide LAR on the IGF-system compared with tamoxifen monotherapy. European Journal of Cancer 200541 694-701. (doi:10.1016/j.ejca.2004.12.015)

Received 13 October 2013

Revised version received 8 December 2013

Accepted 17 December 2013 